\title{
REAL ID: privacy concerns still a factor, but weakly so
}

\author{
Sarah N. Keller ${ }^{1}$ (D) Timothy J. Wilkinson ${ }^{2} \cdot$ A. J. Otjen ${ }^{3}$
}

Received: 20 May 2020 / Accepted: 20 August 2020 / Published online: 7 September 2020

(C) Springer Science+Business Media, LLC, part of Springer Nature 2020

\begin{abstract}
Statewide research conducted to design a campaign to inform Montana residents about the REAL ID Act supported previous claims that some Rocky Mountain residents view the law as an invasion of privacy. Although most Montana residents $(60 \%, n=194)$ planned to get their REAL IDs within the first year that it became available, $43 \%(n=141)$ of respondents to a survey of registered voters $(n=325)$ intended to wait more than one year or never obtain it. Individuals who planned to wait were more likely to report concerns about government collection of personal data, and view the law as an invasion of privacy. However, the relationship is weak. As one of several states that opposed adoption of the Real ID Act in, Montana was characterized in academic and lay media as basing its opposition on concerns about violations of privacy. State officials were so concerned that residents would object to the imposition of the new ID, that REAL ID campaign organizers were directed to only raise awareness, and avoid any efforts at persuasion. Focus groups conducted to assess responses to several campaign strategies indicated an approach that described REAL ID as consistent with traditional Montana values of independence, but did not confront privacy concerns. This paper uses quantitative and qualitative data in an attempt to understand how strong such resistance in Montana actually was.
\end{abstract}

Keywords Privacy · Government control · Social marketing · REAL ID · Terrorism • National resilience

Timothy J. Wilkinson twilkinson@whitworth.edu

Sarah N. Keller

skeller@msubillings.edu

A. J. Otjen

aotjen@msubillings.edu

Extended author information available on the last page of the article 


\section{Introduction}

Were privacy concerns the true basis for opposition to the REAL ID at the state level? Was the opposition based on authentic popular sentiment, or was anti-REAL ID legislation the result of political grandstanding and social advocacy by coalitions who stood to benefit from the resistance? With the 2021 deadline for federal REAL ID compliance upon us, Montana and 21 other states that initially rejected the law are now under a federal mandate to comply. Out of all the states, Montana was one of the last to implement the REAL ID Act. State politicians strongly resisted and publicly voiced their objections to the Act for several years, creating an uncertain environment concerning how the public would adopt the upcoming changes. In an effort to understand the key drivers of such resistance nationally, Regan and Deering (2009) found that the REAL ID was more likely to be opposed by less populous and less wealthy states, which are more vulnerable to unfunded mandates, and by more conservative states, where there is more likely to be a concern about retaining state control. In addition, “....states with stronger privacy orientations were also more likely to pass bills or resolutions in opposition" (Regan and Deering, p. 477).

On the other hand, our research indicates majority support for the law and a general willingness to comply. Only a minority of respondents expressed any concerns about privacy, and such concerns were only loosely associated with resistance to comply. Federalist scholars have asserted that one source of state resistance to federal control can come from well organized social activists at the state level (Krane 2007). Other factors of state resistance to centralist policies, such as REAL ID, include the overstepping of traditional or established state-federal relations; a balance of Republican and Democratic voters that frequently results in practical legislation at the state level; or a rise of common economic and social problems experienced by states.

Understanding the sources of apprehension about the REAL ID Act became necessary once state officials were tasked with implementation. Although talk of "national resilience" became a central theme of preparedness discourse worldwide after the September 11, 2001 terrorist attacks, individual psychological responses to national mandates in the United States have remained resistant. Bean (2018) writes:

Within these frameworks, the concept of resilience is rhetorically transformed from an individual psychological response to trauma into a shared social phenomenon at a national level. This transformation potentially offers citizens a psychic balm in the wake of disaster and in the midst of mourning. Yet, how communication facilitates or hinders this process remains murky (Bean 2018, p. 23).

Because of the anticipated opposition to national or state mandates that affect individual behaviors of any type, state governments, naturally, were leery of potential backlash reactions to the REAL ID law. Recent confusion concerning collective responses to the COVID-19 pandemic highlight similar challenges of messaging effectively for collective action in the United States. Bean (2018) recognizes the dearth of scholarship or advice on national resilience messaging and calls for communication scholarship that addresses the social, psychological, and behavioral implications of resilience-related messaging. A statewide survey and focus groups were, therefore, conducted at the 
request of the Motor Vehicle Division in Montana to guide the state on how to develop an advertising campaign to promote a smooth transition to the new identification cards.

This paper proceeds in the following order. First, we describe the content of the REAL ID Act, how it came into existence, and privacy concerns regarding its implementation. We then describe the qualitative and quantitative methodologies that were employed to design a promotional media campaign to raise awareness about the REAL ID. A findings section is then presented followed by a discussion of practical implications.

\section{Background}

In July of 2002, the newly founded Department of Homeland Security wrote the National Strategy for Homeland Security in response to the September 11th attacks (National Conference of State Legislatures n.d.). This strategy, endorsed by President George W. Bush, specifically included plans to "coordinate suggested minimum standards for state driver's licenses" as a state-level measure to ensure national security (Department of Homeland Security 2002, xi; Department of Homeland Security 2018). Mentions of setting standards for identification were also in the July 2004 9/11 Commission Report (National Conference of State Legislatures n.d.). In December 2004, the Intelligence Reform Legislation before the REAL ID Act was signed into Law under the Emergency Supplemental Appropriations for Defense, the Global War on Terror, and Tsunami Relief (National Conference of State Legislatures n.d.).

In May 2005, Congress passed the REAL ID Act also recommended by the 9/11 Commission. The new IDs, or a TSA approved alternative form of identification, such as a passport or federal ID, are now required to fly within the U.S. or to access certain federal facilities or nuclear power plants. Delays in obtaining the ID may create confusion at airports if residents, relying on previous forms of identification, are turned away from purchased flights.

While this bill contains a range of topics from military spending and disaster relief to agricultural issues, the REAL ID Act itself, labeled as Division B of the law, focuses on security measures including Title II, which specifically addresses standards for identification (United States Congress, Senate 2005, p. 311). It is sandwiched between Title I - Amendments to Federal Law to Protect From Terrorist Entry (302), and Title III Border Infrastructure and Technology Integration (316). Also included in the REAL ID Act are Title IV - Temporary Workers (318) and Title V-Other Change to Provisions Governing Non-Immigrant and Immigrant Visas (321).

In the REAL ID Act (Department of Homeland Security 2017), the purpose of Title II was to make sure people are who they say they are when they apply for an ID card, and to make sure the information would be easy to access and cross-reference if the need arises. The standards include "physical security features designed to prevent tampering, counterfeiting, or duplication of the document for fraudulent purposes," recording a digital image of the person's face, saving digital copies of all related documents, and requiring the information be stored digitally in a database (United States Congress, Senate 2005, pp. 312-313). The Act provides specifies information that states should display on the front of their drivers licenses/IDs, including an individual's full legal name, date of birth, and gender, among other information. States 
are also required to include physical security features to prevent tampering or use of the license/ID for fraudulent purposes, and a common machine-readable technology element as well. Prior to the adoption of the Act, state and local governments maintained wide discretion over their individual licenses/IDs (Govindaiah 2006).

The Act also specifies the procedures a state must follow prior to issuing or renewing a license or ID card. Under the act, states must require proof of address, a social security number, and a photo identification document or a document containing both date of birth and full legal name, such as a birth certificate. Additionally, states must verify that the applicant is a U.S. citizen or legally present in the country, confirm the validity of the individual's social security number, and maintain motor vehicle databases that are linked to those of all other states, effectively creating a national database.

\section{Costs $\&$ inefficiencies}

When the bill was enacted, only seven states adopted the REAL ID without any objection. Given the widespread opposition to the REAL ID, it became prudent for state agencies tasked with implementation to identify the sources of resistance. An analysis of news reports and academic literature on the topic indicates that some of the opposition was related to costs and inefficiencies. The objections raised by legislators in states that adopted statutes or resolutions against the act immediately following the Department of Homeland Security's disclosure of the REAL ID rules revealed just how costly implementation would be (Regan and Deering 2009). In a 2008 U.S. Senate hearing about the act, Senator John Tester (D-MT) voiced concern that states would be forced to take costly measures such as building databases, redesigning licenses, and retraining DMV employees with no hope for reimbursement from the federal government (United States Senate 2008, p. 7). Anti-REAL ID legislation adopted at the state level commonly resulted from action by state DMV officials in concert with privacy and social activists approaching state legislators about the impending costs and complications, such as understaffing of DMV offices and long lines.

However, since opposition was so widespread, there may have been more at stake than just costs and inefficiencies. Davenport (2008) described the anti-REAL ID movement as a modern day version of the Boston "Tea Party," indicating a popular resistance to over-reaching authority. Such concerns about coercive federalism - a break from traditional mores about the relationship between state and federal governments - may differ in nature from abject privacy concerns. If the populace of resistant states was worried about federal interference there would be little that state motor vehicle agencies could do to resolve those concerns. An assessment of popular apprehensions about REAL ID was therefore undertaken to clarify how the motor vehicle division in Montana should conduct its efforts to introduce the new identification as smoothly as possible. This study of attitudes and beliefs about the REAL ID law is the subject of this paper.

\section{Privacy concerns}

The REAL ID was considered a challenge for states to introduce because of a widespread belief in the United States that individuals have a right to know what data 
has been collected about them and to decide the extent to which information is shared. Two competing societal values, security and privacy, are mediated by institutions of the State (Abeyratne 2013). It is clear that the introduction of Real ID brought these two competing values to the fore by raising a number of privacy issues - a national ID, the threat of identity theft through shared databases, and the fear of government surveillance (Govindaiah 2006):

"The main concern with the REAL ID Act's DL/ID provisions is that a much larger group of entities and individuals than ever before will have access to private information....Because of the ubiquitous use of DLs/IDs, the government must require protection of the common machine-readable technology so that unauthorized entities cannot access the information that the technology contains. Furthermore, even if authorized entities access the information encoded on DLs/ IDs, there is no guarantee that these entities would use it in authorized manners." (Govindaiah 2006, p. 205).

Proposals to introduce a national ID have been consistently rejected by both Congress and the public since the 1970s (Regan and Deering 2009). Montana Senator John Tester co-sponsored S. 717, a proposed federal alternative to the bill, and expressed disapproval of the REAL ID Act in a 2008 hearing:

"I have got some pretty strong emotions about REAL ID. It is, as I see it, the worst kind of Washington, DC boondoggle.... REAL ID was enacted with no debate or chance to amend it. In the 3 years since the law was enacted, it has had all kinds of unintended consequences and no benefit whatsoever when it comes to making America more secure at this point. It is incredibly expensive and complicated. It is burdensome to States and individuals alike. And it is being implemented in a style that makes ordinary folks cringe" (United States Senate 2008, 6).

Tester also expressed concern that that the new IDs would lead to a national ID card and, rather than believing the cards would protect Americans, (echoing Senator Akaka's concerns) would lead to identity theft (United States Senate 2008, p. 7). In many states, anti-Real ID statutes included phrases describing the Act as an invasion of privacy, while other state resolutions or bills specifically referred to fears of government surveillance or identity theft that might result from the shared database system the act requires. Yet, there is no data reporting the popular opinion on these matters.

\section{Social advocacy groups}

If public opinion on the REAL ID was unknown, who stood to benefit from rejecting it? A host of social advocacy groups might fall into this category, including the American Civil Liberties Union, the Center for Democracy and Technology, the National Immigration Law Center, the National Council of La Raza, and the National Coalition Against Domestic Violence, among others. Religious groups such as the Amish, the Old Order Mennonites, and Native American groups also opposed the law. Coalitions of social advocacy groups were often successful at getting one or more 
members of a state's legislature to put the issue on the agenda and build support among colleagues.

\title{
Theory
}

Over the last decade, states gradually came into compliance, and now all 50 states have issued REAL IDs (Department of Homeland Security 2017). In May of 2017, Montana passed HB 366, allowing Montanans the option to obtain a REAL ID, amending the 2007 law rejecting the REAL ID Act (Montana State Legislature 2007a, 2007b). Scholars have not attributed resistance to REAL ID to a single factor. Although hype in popular media alleged that opposing states were strong in privacy orientation, federalist scholars make it clear that public reaction to the act has been much more nuanced. The complexity of popular resistance to federal involvement provided little guidance for state agencies that were tasked with gaining compliance from their residents. Thus, the need for effective communication strategies on the part of state governments was crucial in order to achieve compliance by the public.

Informational models of communication may give some advice to policy-makers seeking to find effective message strategies for resilience in the wake of disasters (e.g., terrorism, pandemics or natural disasters) in the United States. As Bean (2018) writes:

\begin{abstract}
Drawing from an 'informational model' of communication that emphasizes pre-, during-, and post-disaster information seeking and processing, applied communication researchers can make important contributions to understanding how message strategy, dissemination, and exchange might shape social, psychological, and behavioral manifestations of national resilience via citizens' cognitive and affective responses (Bean 2018, p. 25).
\end{abstract}

The Transmission Model of Communication (Shannon and Weaver 1949) envisioned information transmission as a technical process, from a source, through a channel, to a receiver, affected only by "noise," which might include crackling from a wire. The model was used to maximize information transmission through telephone and radio waves, but it left out many human factors that can interfere with the transmission or receipt of a message. Although the concept of "noise" does make some allowance for the ways in which messages may be changed in the process, Shannon and Weaver frame the issue of noise in terms of incidental interference, rather than in terms of a central and purposive process of interpretation. The case of REAL ID opposition exhibits how voices from special interest groups, culture, tradition, and personal beliefs can also influence message interpretation.

More recently, McGuire (2000) introduced the Input-Output Framework for persuasion, which depicts communication as a result of successfully transmitting information through several steps or phases. In this model, the success of message transmission is influenced by culture, bias, and context, at least to some extent. The inputs are the different aspects of the persuasion/communication attempt (e.g., source, message, channel, receiver, context), and outputs are the stages of persuasion (e.g., attention, liking, yielding, deciding, acting, reinforcing, consolidating), which measure how 
persuasive the communication has been. Communication scholars may be able to study the successes and failures of national resilience conversations or campaigns with regard to these various inputs and outputs to identify strategies for future endeavors.

The current study employed the Risk Behavior Diagnosis scale (Witte 1996) to identify barriers to change and perceptions of efficacy at the individual level. The variables were used to assess whether popular resistance to national public safety efforts around REAL ID could be overcome through increasing the audience's perceived severity of the threat of terrorism and by carefully crafting message design. Witte (1996) argues that - when faced with any threat - audiences must feel capable and confident in their personal ability to make a change and believe that such changes will make a difference on a grand scale. If audiences truly felt that REAL IDs would make them safer, they would be more likely to act. Similarly, if audiences felt that privacy concerns were less important than national security, and that the REAL ID would contribute to security, they would be more likely to act. Because there are multiple factors that could lead to REAL ID opposition, we decided to test whether privacy really was a strong factor.

This discussion leads to the following hypothesis:

- H1: Privacy concerns are associated with the timing of the intent to obtain the REAL ID.

\section{Methods}

In spring of 2017, the Motor Vehicle Division of the Montana Department of Justice contracted with two Montana university professors to administer a statewide online survey to collect data and assess the current awareness and understanding of REAL ID. We used the survey to identify common misperceptions about the law, types of confusion, frustration, and resentment. In addition, the survey was designed to identify common barriers to obtaining the new ID, and approximate numbers of those who planned to obtain a new ID in the first year it became available. The results would be used to design an informational campaign to clear up confusion in order to reduce congestion at driver's license agencies or frustrations during travel. The survey was designed using the Risk Behavior Diagnosis (Witte 1996), an informational model of persuasion, to identify sources of resistance to the REAL ID in order to improve the MVD's ability to influence public behaviors. The data was intended to inform a statewide REAL ID advertising campaign to be designed by university students and paid for by the MVD.

The study was approved by the university's Institutional Review Board, given that respondents remained anonymous and neither professor received any personal compensation for the study; all funds provided by the MVD were used to purchase the mailing list and hire a research assistant. A random sample of 4000 was generated from a statewide list of registered voters. Respondents were contacted online by Gravis Marketing, a market research company hired for the project, and invited to complete the survey anonymously through a link to Qualtrics Survey Software. The instrument probed on attitudes and awareness of Real ID. Approximately 400 responses were obtained, skewed towards a more senior and educated demographic than the state 
population. (Responses were interpreted with this precaution in mind, by considering how the older, more affluent characteristics of the sample might influence responses. Once it was discovered that both upper income and lower-income individuals were less likely to be enthusiastic adopters, we felt confident that the sample would show, if anything, more reluctance to adopt REAL IDs than might be present in the population. The fact that age was not correlated with our attitudinal outcomes indicated that age was not a significant source of bias).

No experimental design was employed. We used analysis to identify predictors of the timing of intent to obtain, which became our dependent variable. Results were analyzed using SPSS software to identify the frequencies of common barriers to the ID, frequencies of early vs. late adopters, and segments of the population who might inadvertently delay too long and encounter frustrations in travel or entering federal facilities. Ordinal logistic regression was used to identify predictors of variance in the timing of intent to obtain a new ID. In this analysis, the timing of the intent to obtain was used as dependent variable, and all other variables were treated as independent variables.

Once survey results were analyzed, and key barriers identified, draft campaign messages in the form of public service announcements for radio, TV, and social media were created, including "Kids Get Through," "I'm In A Hurry," "IDIDID2" and "Real Life." The advertisements were designed to raise awareness of the REAL ID, clarify the process for adoption, and to dispel dominant rumors. Focus groups were conducted with members of the general public to pre-test the ads. In all, five focus groups were conducted with 49 respondents, ranging in age 17-59. Prompts were used to find out whether respondents were aware of the new law, how they felt about it, and, once shown draft ads, how they felt about them in terms of emotional response, clarity, and attitudes towards the REAL ID. Specifically, respondents were asked if the ads made them feel more or less positive about the new law, more or less secure with the new IDs, more or less confident in the ease with which they could obtain a REAL ID, and more or less willing to adopt one as soon as it became available. Responses were recorded and transcribed for analysis.

Four focus groups $(n=40)$ were conducted to review the first round of draft messages, ( $4 \times n=5-10$, ages 18-55). About one-half the participants were unaware of the Real ID prior to participating in the focus groups; others were aware but not knowledgeable. One focus group was conducted online, in a Zoom meeting. Participants were read the text for each PSA and feedback was solicited and recorded after each one. All four PSAs created different responses and reactions from the participants. PSAs were revised accordingly. A fifth focus group ( $n=9$, ages 17-59) was conducted after the first round of draft messages were revised, producing the "Real Me" slogan and "Lewis and Clark" ad concept.

\section{Results}

\section{Survey participant characteristics}

Most survey respondents were retired, ages 56-75, held a bachelor's degree, and selfidentified as either Independent or Democratic in terms of party affiliation (Table 1). 
Table 1 displays key demographic characteristics of respondents in the study. The majority of respondents were males $(53.2 \%)$ with females making up $46.2 \%$ of the sample. The age of respondents skewed high, with $60.8 \%$ aged 56 and above. The largest annual income category is $\$ 50,000-\$ 74,000$, which is $22.8 \%$ of respondents. For the key variable under consideration, privacy [the perception that the Real ID is an invasion of privacy], 94 respondents, or $28.6 \%$ of the respondents indicated agreement, while $235(71.4 \%)$ of respondents did not agree with this statement.

\section{Dependent variables}

Table 2 displays the frequencies for the dependent variable, Timing of Intent to Obtain, which consists of six, ordinal categories that are responses to the question: "Once available, how soon do you intend to get your REAL ID? These are $1=$ never $(17.6 \%), 2=$ more than 1 year $(24.6 \%), 3=7$ months -1 year $(11.2 \%), 4=2-6$ months $(13.4 \%), 5=3$ weeks1 month $(15.8 \%)$, and $6=$ immediately $1-2$ weeks $(17.3 \%)$. Because common methods variance is a consideration when self-report surveys are used to measure relationships between variables (Spector 2006), several actions were taken to ameliorate this concern. The questionnaire was written in a way that lessens this potential problem through the selection of qualified respondents (MacKenzie and Podsakoff 2012), careful wording of each item (Tourangeau et al. 2000), and separating scale items for the variables of interest in the study (Podsakoff and Organ 1986). The use of single-item measures, like intention, which constitue concrete constructs, is supported in the literature (Bergkvist 2015).

Table 1 Demographic and other Characteristics

\begin{tabular}{llll}
\hline Variables & Categories & Frequency & Percentage \\
\hline Sex & Male & 173 & 53.2 \\
Age & Female & 152 & 46.2 \\
& $18-25$ & 4 & 1.2 \\
& $26-35$ & 10 & 3 \\
& $36-45$ & 27 & 8.2 \\
& $46-55$ & 57 & 17.3 \\
Annual Income & $56-65$ & 100 & 30.4 \\
& $66-75$ & 100 & 30.4 \\
& $76-$-up & 31 & 9.4 \\
& Under $\$ 10,000$ & 8 & 2.4 \\
& $\$ 10,000-\$ 29,000$ & 34 & 10.3 \\
& $\$ 30,000-\$ 49,000$ & 60 & 18.2 \\
& $\$ 50,000-\$ 74,000$ & 75 & 22.8 \\
& $\$ 75,000-\$ 99,000$ & 41 & 12.5 \\
& $\$ 100,000-\$ 249,000$ & 44 & 13.4 \\
Real ID is an invasion of privacy & $\$ 250,000$ 0r more & 3 & 9 \\
& Prefer not to say & 64 & 19.5 \\
& Yes & 94 & 28.6 \\
& No & 235 & 71.4 \\
\hline
\end{tabular}


Table 2 Dependent Variable. Once available, how soon do you intend to get your REAL ID?

\begin{tabular}{lcccc}
\hline Timing of Intent to Obtain & Frequency & Percent & Valid Percent & Cumulative Percent \\
\hline Never & 58 & 17.6 & 17.6 & 17.6 \\
more than 1 year & 81 & 24.6 & 24.6 & 42.2 \\
7 months - 1 year & 37 & 11.2 & 11.2 & 53.5 \\
2 month -6 months & 44 & 13.4 & 13.4 & 66.9 \\
3 weeks - month & 52 & 15.8 & 15.8 & 82.7 \\
immediately 1-2 weeks & 57 & 17.3 & 17.3 & 100.0 \\
Total & 329 & 100.0 & 100.0 & \\
\hline
\end{tabular}

\section{Independent variables}

Based on the literature, the survey instrument contained 12 items intended to measure attitudes about the REAL ID and personal safety. These twelve items were included in a factor analysis. Factor analysis is used to remove redundancy in a set of correlated variables by producing a smaller of derived variables (Kachigan 1991). Several tests for were used to examine the validity of the factor analysis. Table 3 displays the result of a Kaiser-Meyer-Olkin (KMO) test which measures sample adequacy, as well as Bartlett's test of data sphericity. The KMO score of .906 is above the recommended value of 0.5 , and the Bartlett test is significant, meaning that the variables included in the correlation matrix are significantly different from zero. Thus, we are confident that the variables were significantly correlated.

Table 3 shows that $62 \%$ of the variance in the 12 variables was reduced to three factors with eigenvalues greater than 1: "Enthusiasts," who embraced the law; "Relaxed," who already feel safe but have no opposition to the law; and "Independents," who are concerned about personal safety but reject the law. We used the most common rotation technique, varimax rotation, in order to maximize the variance of the squared factor loadings on the variables. Although opinions differ on the proper cutoff score for factor loadings, we follow (Hair et al. 1998) and simply use .6 and above as the indicator for which items should be included in our interpretation of the factors. The first factor, which is composed of six items with component scores greater than .60, consists of items indicating positive attitudes about the Real ID. We have labelled this factor Enthusiasts. The second factor, consisting of two items greater than .60, has been labelled Relaxed. We exclude the third factor, Independents, from further analysis because it consists of two, incongruent items that make up only $8 \%$ of the variance. The factor analysis scores were saved as two variables and are included as independent variables in an ordinal regression equation. The variable of interest, privacy, is a dummy variable responding to an item that states, "The REAL ID is an invitation of privacy."

\section{Ordinal logistic regression}

Table 4 presents the results of ordered logistic regression for the sample, using the same dependent variable, Timing of Intent to Obtain, measured by responses to the question, "Once available, how soon do you intend to get your REAL ID?" Of the control variables, annual incomes under $\$ 10,000$, between $\$ 75,000-\$ 99,000$ and $\$ 250,000$ or 
Table 3 Factor Analysis

Rotated Component Matrix ${ }^{\mathrm{a}}$

Items

Component

123

If REAL ID were available today, I would likely to get it

$.851-.008-.082$

I am willing to comply with the REAL ID Act

$.845 \quad .020 \quad .032$

I would recommend getting a REAL ID to a friend or colleague

$.832 \quad .076-.056$

Montana should quickly accept the REAL ID

$\begin{array}{lll}.802 & .260 & -.039\end{array}$

The REAL ID will make it easier for me to travel

$\begin{array}{lll}.760 & .164 & -.099\end{array}$

The REAL ID Act is going to contribute to national security

$.635 \quad .390 \quad-.036$

I understand that Montana will maintain my data in safe storage where the federal

$\begin{array}{lll}.540 & .359 & -.142\end{array}$ government does not have access

I already have a driver's license and a passport, so I don't need a REAL ID

$-.521-.031 \quad .434$

Traveling in the US is safe

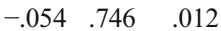

The REAL ID Act is easy to understand

$.413 \quad .645 \quad-.131$

The Motor Vehicle Department is too much of a hassle to go and get a REAL ID

$-.180-.347 \quad .725$

Safety for myself and/or my family is important to me

$.176 \quad .653 \quad .636$

Extraction Method: Principal Component Analysis.

Rotation Method: Varimax with Kaiser Normalization.

a. Rotation converged in 4 iterations.

Notes: Chi-Square $=34.626$ (p. $<.01$,

more were statistically significant, with negative coefficients in each instance. This means that two of the three categories of higher income respondents intend to delay obtaining the REAL ID. We speculate that it may be that these respondents are more likely to have alternative forms of identification, such as passports, and therefore do not believe they need to urgently respond to the REAL ID deadline. The negative relationship between respondents with incomes under $\$ 10,000$ and Timing of Intent to Respond $(p .<.10)$ suggests that these respondents do not envision flying in the near term or/and do not want to expend their funds or time on obtaining the REAL ID.

Each of the three variables of interest were also significant. Enthusiasts $(p<.05)$ was positively related with Timing of Intent to Obtain, while Relaxed $(p<.05)$ and Privacy $(p<.10)$, were negatively related to the dependent variable. The stronger a person valued privacy, the later they intended to adopt the new ID. Similarly, people in the "Relaxed" factor, who believed that traveling in the United States is already safe, and that the REAL ID is easy to understand, were also likely to wait to adopt it.

In ordinal regression the values of the dependent variable are not in-and-ofthemselves important, but indicate that larger values are associated with higher outcomes (Stata Press 2013). Unlike OLS regression, standardized b coefficients are not used to measure effect size in ordinal regression. Rather, effect size is understood as cumulative odds ratios defined as the probability that the "dependent variable is less than or equal to the given category, divided by ...the probability that the dependent variable is more than the given category" (Garson 2014, 31). For each increasing unit of the independent variable, the odds ration indicates the multiplicative change in odds 
Table 4 Ordinal Regression

\begin{tabular}{|c|c|c|c|c|c|}
\hline \multicolumn{2}{|l|}{ Variable } & \multirow{2}{*}{$\begin{array}{l}\text { Coeffecient } \\
-2.281\end{array}$} & \multirow{2}{*}{$\frac{\mathrm{SE}}{.3005}$} & \multirow{2}{*}{$\begin{array}{l}\text { Wald Chi-Square } \\
57.630 * * *\end{array}$} & \multirow{2}{*}{$\frac{\text { Odds Ratio }[\operatorname{Exp}(B)]}{.102}$} \\
\hline Threshold & [OncAvail = 1.00] & & & & \\
\hline & [OncAvail = 2.00] & -1.262 & .2809 & $20.195 * * *$ & .283 \\
\hline & {$[$ OncAvail = 3.00] } & -.551 & .2725 & $4.083^{* *}$ & .577 \\
\hline & {$[$ OncAvail = 4.00] } & .032 & .2692 & .014 & 1.033 \\
\hline & {$[$ OncAvail = 5.00] } & .583 & .2713 & $4.612 * *$ & 1.791 \\
\hline \multicolumn{2}{|l|}{ Male } & -.302 & .2064 & 2.147 & .739 \\
\hline \multicolumn{2}{|l|}{ Female } & $0^{\mathrm{a}}$ & . & . & 1 \\
\hline \multicolumn{2}{|c|}{ Under $\$ 10,000$} & -1.216 & .7129 & $2.909^{*}$ & .296 \\
\hline \multicolumn{2}{|c|}{$\$ 10,000-\$ 29,000$} & -.283 & .3737 & .573 & .754 \\
\hline \multicolumn{2}{|c|}{$\$ 30,000-\$ 49,000$} & -.318 & .3275 & .942 & .728 \\
\hline \multicolumn{2}{|c|}{$\$ 50,000-\$ 74,000$} & -.164 & .3202 & .261 & .849 \\
\hline \multicolumn{2}{|c|}{$\$ 75,000-\$ 99,000$} & -1.030 & .3705 & $7.726^{* * * *}$ & .357 \\
\hline \multicolumn{2}{|c|}{$\$ 100,000-\$ 249,000$} & -.340 & .3599 & .891 & .712 \\
\hline \multicolumn{2}{|c|}{$\$ 250,000$ 0r more } & -2.142 & .9885 & $4.693 * *$ & .117 \\
\hline \multicolumn{2}{|c|}{ Prefer not to say } & $0^{\mathrm{a}}$ & . & . & 1 \\
\hline \multicolumn{2}{|l|}{ Enthusiasts } & .265 & .1313 & $4.091 * *$ & 1.304 \\
\hline \multicolumn{2}{|l|}{ Relaxed } & -.249 & .1103 & $5.090 * *$ & .780 \\
\hline \multicolumn{2}{|l|}{ Privacy } & -.508 & .2906 & $3.053^{*}$ & .602 \\
\hline
\end{tabular}

Notes: $* * * \leq p<.01, * *=p<.05, * \leq p<.10$

of the dependent variable being in a higher category, holding constant the other independent variables (Crowson 2019). The odds ratio is reported in SPSS as "exp(B). The odds ratio for Enthusiasts is 1.304, indicating that this variable is associated with higher values on Timing of Intent to Obtain, which means that the more respondents are positive about the Real ID the more likely they are to obtain it as soon as they are able to do so. The second variable of interest, Relaxed, has an odds ratio of .780 which, because it is less than 1.0, indicates a decrease in the odds of having a higher value on Timing of Intent to Obtain, indicating that Relaxed respondents will delay getting the Real ID. Finally, Privacy has an odds ratio of .602, which also indicates a negative relationship between this variable and Timing of intent to Obtain. This means that respondents who think the Real ID is an invasion of privacy are more likely to delay obtaining the Real ID. This finding supports our hypothesis: Privacy concerns are associated with the timing of the intent to obtain the REAL ID. Of note, however, the odds ratio is less than the other two variables of interest, which suggests that - while privacy is important to many people - it is not an especially salient driver for adoption of the Real ID.

\section{Focus group results}

Few focus group participants were aware of the REAL ID from newspaper and television news reports; most of the participants without prior knowledge had neutral feelings towards the law. Comments about awareness showed a great deal of confusion 
about the new law, but little opposition. When asked what they knew about the REAL ID prior to the focus group meeting, respondents said, "Didn't know a thing;" "Zero. I know nothing;" and "Well, I have been hearing things. But I thought it had already happened or wasn't going to happen or something. I was surprised to find out that it's just now happening in 2018." In response to the question whether anything remained unclear, respondents again expressed confusion, but not opposition: "Yes, I still don't really get the purpose of it. I know security and such but I would like to know how all that is going to work. Do I lose privacy? Is there a cost? Do they send it to me in the mail or do I get it on the spot at the DMV?" or "I still don't quite understand it all." The extensive amount of confusion that participants voiced indicated that the most valuable information to our target audience would be to provide details on what, when, where, why, how, and price, defining the core product.

Respondents were in agreement that the new IDs would increase national security: "I feel safer. I think it will be harder to fake this ID and so that makes me feel safe," said one 40-year-old female respondent from Billings, MT. "I like anything that might stop terrorism and make us safer. I like the idea of it. I just still don't know much about it," said a 43-year-old male respondent, also from Billings. When asked if they felt the new machine-readable technology is necessary, respondents expressed support for the REAL ID process: "I do. I think that security will become more and more important in the years to come and this is a step in that direction." Another respondent said, "Yea, I like that it is harder to fake. I would like to see one."

Focus group results showed several barriers, including fear of change, fear of sharing personal information, not knowing where to get the new ID and needing more information. When asked which barriers they had towards getting the new ID, only one respondent mentioned privacy concerns, while others talked about inconvenience. "[If I don't get one, it would be] because if someone stole it, they might be able to do something with all my information."

Focus group participants connected most with "The Real Me" slogan and the "Lewis and Clark" ad concept relating to consequences of not having an ID (Fig. 1). "[It's a] Home run," said one respondent. "Love the higher level of security, this is important," said another. "Funny," said a third respondent, and, "[I] Want to see it on the PSA." More positive responses to the Lewis and Clark ad were: "[It] gets my attention and keeps it;" and "[It] made me aware." Positive responses to the "The Real Me" slogan were: "The Real Me is good;" "[The] characters are familiar;" and "[I] can see how it will help prevent identity theft."

\section{Discussion}

Overall, the results of both the survey and focus group research showed that a majority of Montana residents were ready to embrace the new law, and that privacy was only weakly correlated with delays or resistance. Most barriers to the new ID had to do with convenience or confusion. While our findings did confirm that people with strong privacy orientations were less likely to get the REAL ID quickly, it did not show that privacy led to opposition. The strongest predictor of delays or refusal to obtain a REAL ID was income. Residents on the extreme ends of income in the state, both low-income and high-income, were less likely to intend to get a REAL ID soon, or at all. We 


\section{SPOTLIGHT \\ PRODUCTIONS}

CLIENT: Real ID MSU Billings

PROJECT: Lewis \& Clark Airport - TSA

LENGTH: 30 seconds

DATE: $\quad$ March 21, $2018-3 p m$

\begin{tabular}{|l|l|}
\hline VIDEO & AUDIO \\
\hline $\begin{array}{l}\text { Wide Shot - Lewis and Clark } \\
\text { approach TSA checkpoint with } \\
\text { gear, Agent asks for IDs. }\end{array}$ & $\begin{array}{l}\text { Agent: Hello Gentleman, May I see } \\
\text { your Montana Real ID"? }\end{array}$ \\
\hline $\begin{array}{l}\text { Lewium \& Clark introduce } \\
\text { themselves }\end{array}$ & $\begin{array}{l}\text { Lewis: "ID? I'm Captain Meriwether } \\
\text { Lewis." }\end{array}$ \\
\hline $\begin{array}{l}\text { Close up - Clark } \\
\text { Clark: "And I'm Captain William } \\
\text { Clark." }\end{array}$ \\
\hline $\begin{array}{l}\text { Close up - Agent shakes his head, } \\
\text { directs their attention to SIGN with } \\
\text { information about website \& } \\
\text { documentation needed for Real ID }\end{array}$ & (airport sound continues) \\
\hline $\begin{array}{l}\text { Three shot - Lewis, Clark and } \\
\text { Agent as he looks through list }\end{array}$ & $\begin{array}{l}\text { Agent: Hang on, I see more than } \\
\text { one William Clark in the database. }\end{array}$ \\
\hline $\begin{array}{l}\text { Wide shot - Alarm goes off and } \\
\text { TSA agents start to surround them. }\end{array}$ & $\begin{array}{l}\text { (Sound of Alarms going off. Alert, } \\
\text { Imposter Alert.) }\end{array}$ \\
\hline $\begin{array}{l}\text { Lewis and Clark raise their hands } \\
\text { to surrender. }\end{array}$ & Clark: It's the real me, I promise. \\
\hline MVD Official talks to camera & $\begin{array}{l}\text { MVD Official: Discover more at } \\
\text { MT REALID.gov, available } \\
\text { January, 2019. }\end{array}$ \\
\hline $\begin{array}{l}\text { Montana Real ID Logo } \\
\text { MTReaLID.gov } \\
\text { The Real Me }\end{array}$ & $\begin{array}{l}\text { Clark: Montana Real ID } \\
\text { It's the Real Me. }\end{array}$ \\
\hline
\end{tabular}

2120 Sunnyview Lane • Billings, MT 59102 • 406.698-8278 • anne.gaver@spotlightads.com

Fig. 1 Script from Lewis and Clark Airport television public service announcement

presumed this was because low-income people are less likely to fly and high-income people often have passports, which can substitute for REAL IDs in most circumstances.

Focus groups conducted to pre-test the ads indicated how important it is to connect to Montana values of independence, tradition and safety. The university team created a 
campaign featuring historical characters familiar to Montanans, Lewis and Clark, relaying the most relevant information in a straightforward and direct manner (Figs. 2 \& 3). The branding and slogan, "The Real Me," appeals to the sense of authenticity important to Montanans, and emphasizes the role REAL ID plays in national security (Figs. 4 \& 5). The campaign theme revolved around Lewis and Clark transported into modern times. The characters of Lewis and Clark find themselves in situations where they would need a REAL ID, such as trying to fly to avoid using their canoe or hiking. This campaign plays on the fact that Montanans tend to be familiar with the Lewis and Clark expedition as state history, and the idea of the old coming into the modern times (Fig. 6). The goal was to use the Lewis and Clark characters to raise awareness about REAL ID and drive the audience to visit the website (www.mtrealid. gov) to learn more about it (Figs. $7 \& 8$ ).

Campaign organizers were initially in disagreement with the Montana Motor Vehicle Division officials about whether the ads should attempt to dispel fears that the REAL ID is a violation of privacy (Vehicles, Montana Division of Motor 2018). In the end, the campaign would focus on only raising awareness, and avoid addressing common myths or anti-REAL ID perceptions. Because the goal of the campaign was to raise awareness rather than promote the product, the creative concepts had to focus on encouraging people to take measures to learn more about REAL IDs and avoid coming across as a public mandate.

However, the baggage surrounding Montana's REAL ID implementation had to be considered in creating the campaign (Montana State Legislature 2007a, 2007b; Justice, Montana Department of 2014). Given how hard the state fought against it, a significant portion of the public also became resistant. In order to adopt the REAL ID, once all extensions had been exhausted, state officials needed to backpedal and encourage residents to accept the change that state legislators had previously worked so hard to

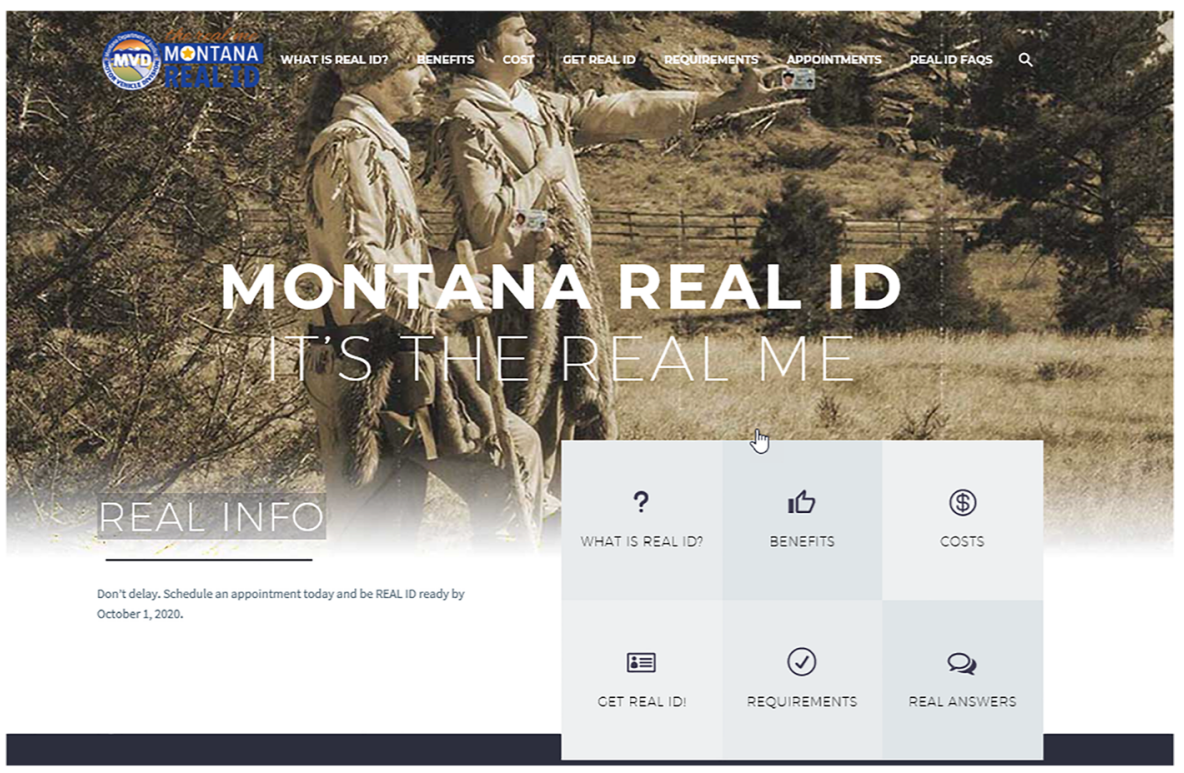

Fig. 2 Screenshot from www.MTrealid.gov website. 


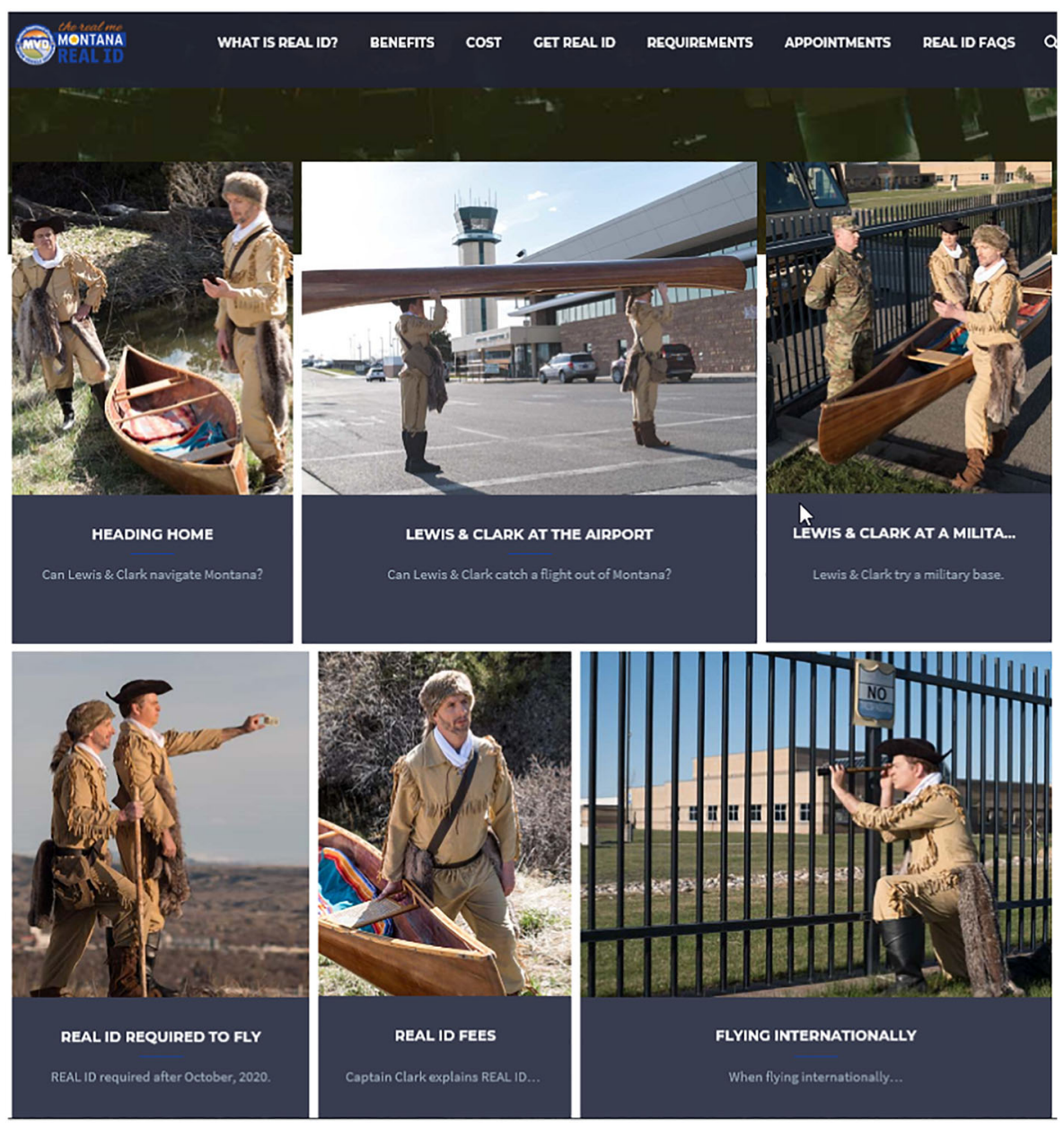

Fig. 3 Screenshot from links to campaign ads on www.MTrealid.gov website

avoid. With that in mind, researchers probed focus group respondents to identify the appropriate tone of voice for the campaign. Participants thought the campaign should strike a balance between urgency and leniency - simultaneously instilling a sense of urgency and gravity about the role REAL IDs can play in protecting national security, while avoiding any messages that could be perceived as too forceful or top-down (Otjen and Ollivant 2018; Keller 2017). Such a strategy was consistent with significant changes in public discourse about national security since the terrorist attacks of September 11, 2001.

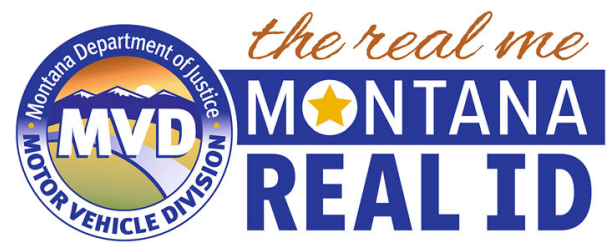

Fig. 4 Screenshot from user subscription links and about us section of website 


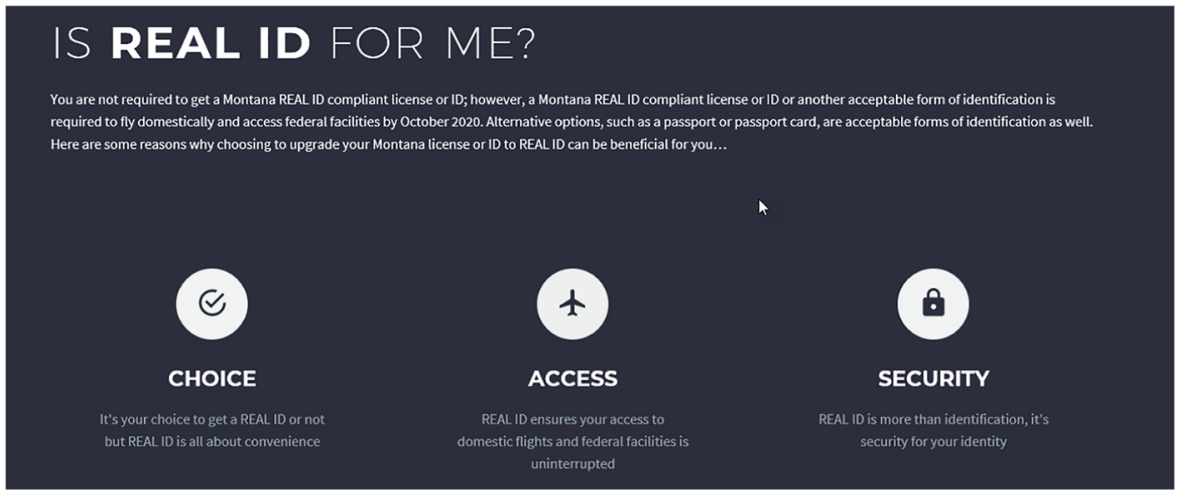

Fig. 5 Categories of information for users of www.MTrealid.gov website

The term, "national resilience" has become a key phrase behind which the U.S. public can unite, both in the contexts of natural disasters and rising numbers of terrorist attacks (Bean 2018). The term implies a societal - rather than individual - focus on recovery and resistance to trauma. The shift advocates for public initiatives - legislative, technological and cultural - that can help the nation withstand and prevent external threats. In the wake of such changes in public conscience - a charge towards endurance, fortitude, stoicism, and resolve - it is possible that previously held concerns about
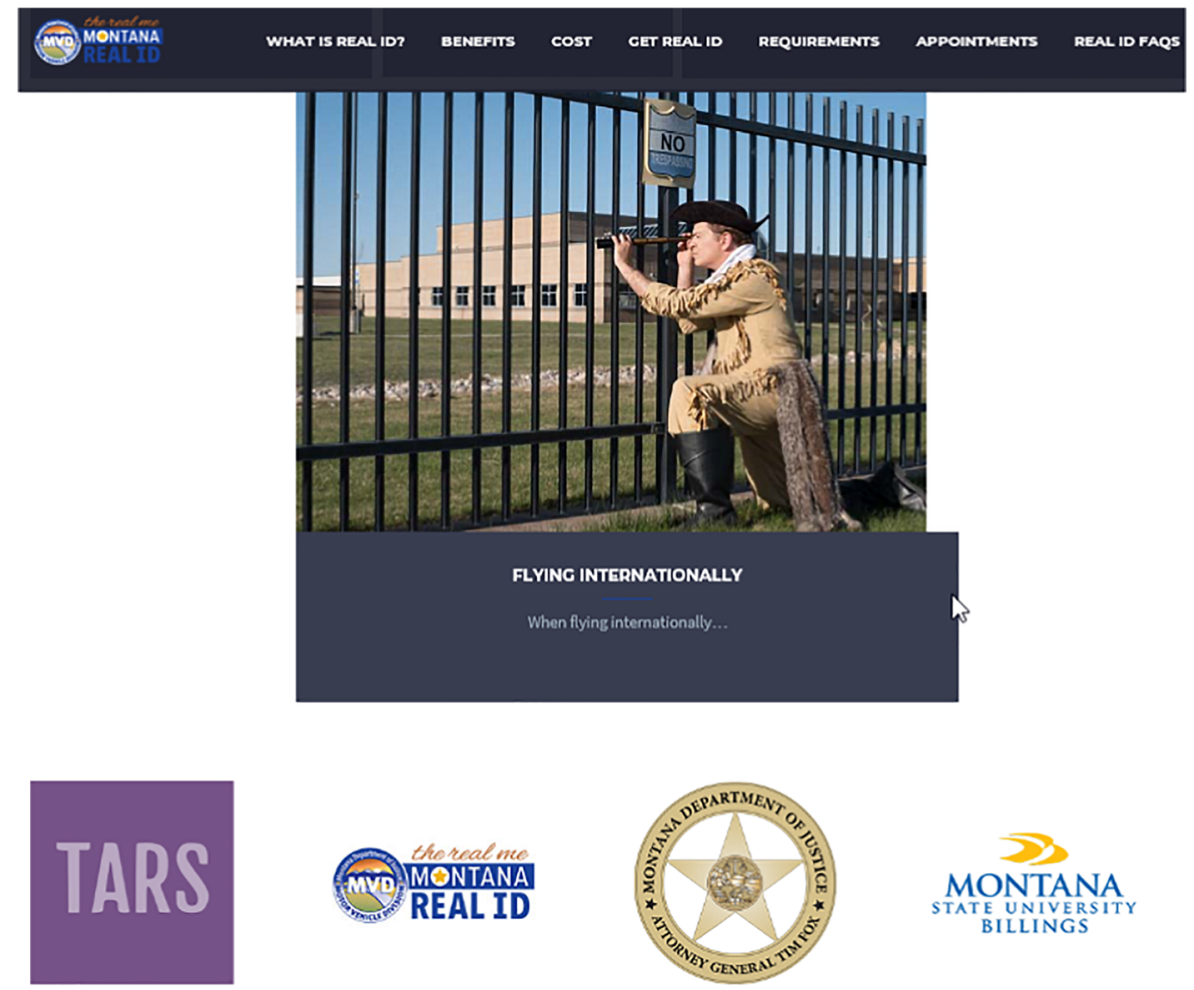

Fig. 6 Still from Lewis and Clark Airport television public service announcment 


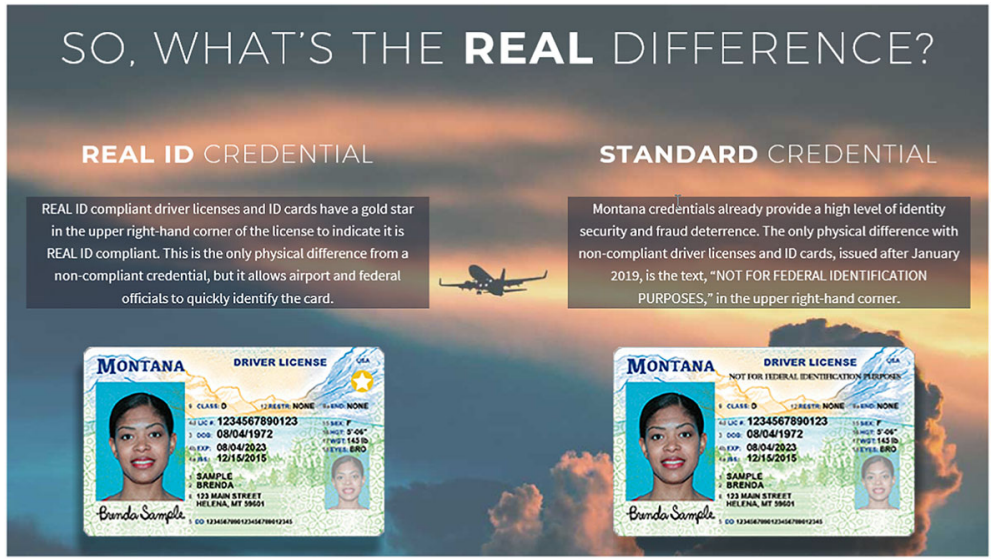

Fig. 7 Image showing a comparison between a standard driver's license and the REAL ID

privacy have abated. Indeed, our data indicate a populace in an opposition state ready to embrace the REAL ID act, once all available extensions ran out, despite having been one of the 10 states most strongly in opposition. Applied communication scholarship is needed to explore the relationship between the social, psychological, and behavioral manifestations of national resilience and citizens' attitudes towards identity, privacy and government control (Bean 2018).

The lessons learned through this study can be used to inform the current federal failure to lead the nation to public safety in fighting the Coronavirus pandemic. It is clear that the U.S. public and lawmakers have a strong anti-federalist sentiment and are resistant to top-down federal measures, especially when such mandates interfere with individual lifestyle behaviors. While other nations have successfully transformed the individual psychic trauma of the COVID-19 pandemic into a shared national phenomenon, invoking the rhetoric of resilience, the United States' strong ethos of individual

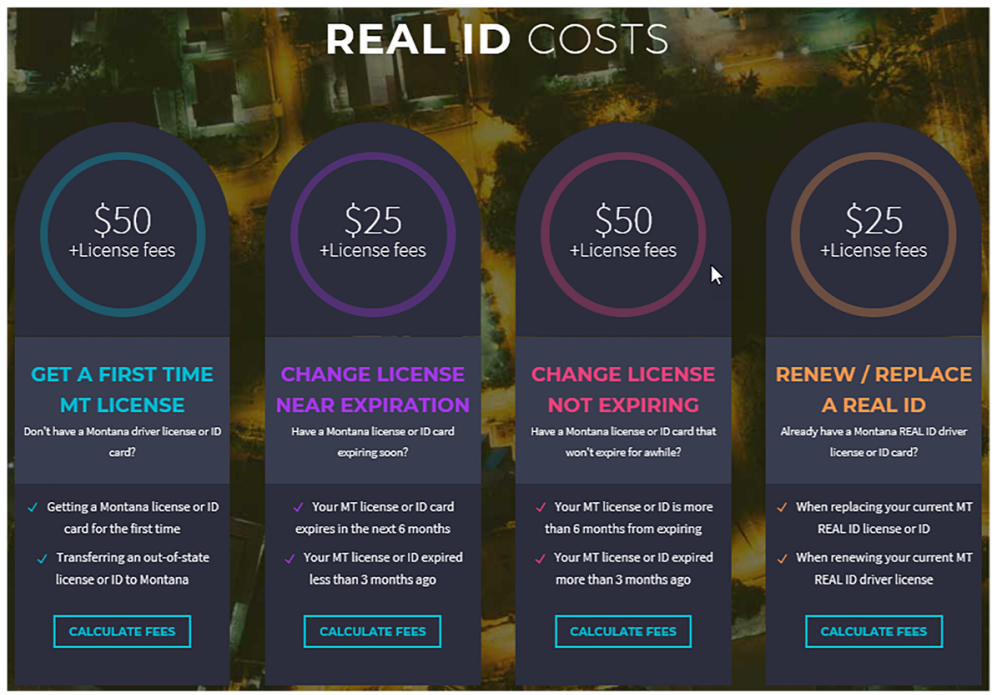

Fig. 8 Website page showing the costs associated with different categories of licenses and renewals 
freedom - taken to the extreme - has interfered with such collective actions or mindsets. Rhetoric of a collective mindset was similarly used to invoke national responses to terrorist threats in such countries as Australia, New Zealand, Japan, Malawi, Israel and Singapore in the wake of 9-11.

Our findings indicate that, when confronting a national threat that requires lifestyle behavior change on a societal level, messages of urgency need to strike a balanced, unbiased tone; a tone that simultaneously communicates caution and invokes our traditional values of independence and freedom. If the threat of terrorism can ultimately prompt the U.S. public to put down the sword of privacy and adopt REAL IDs, then the threat of COVID-19 should be able to inspire us to envision a society free of this virus as consistent with our goals of freedom and public safety.

Funding This work was supported by a grant from the Montana Department of Justice, Motor Vehicle Division.

\section{References}

Abeyratne R (2013) The ePassport - new technology to counter security threats. J Transp Secur 6:27-42

Bean H (2018) National resilience. J Appl Commun Res 46(1):23-25

Bergkvist L (2015) Appropriate use of single-item measures is Here to stay. Mark Lett 26:245-255

Crowson, Mike. 2019. Ordinal Logistic Regression Using SPSS. https://www.youtube.com/watch?v= rSCdwZD1DuM; https://drive.google.com/file/d/19TriKKQ8tzwrhGoYr_LxmpfpAjSTW3Ov/view

Davenport, Paul. 2008. "Legislature votes to opt AZ out of real ID.” The Tuscan Citizen, June 11

Department of Homeland Security. 2002. "National Strategy for homeland security." Department of Homeland Security. July. https://www.dhs.gov/sites/default/files/publications/nat-strat-hls-2002.pdf

Department of Homeland Security 2017. "Real ID." The Department of Homeland Security October 2. https://www.dhs.gov/real-id

Department of Homeland Security 2018. Real id. March 8. https:/www.dhs.gov/real-id-public-faqs

Garson GD (2014) Logistc regression: binary and multinomial. Statistical Associates, Asheboro, NC

Govindaiah, Manoj. 2006. "Driver licensing under the real ID act: can current technology balance security and privacy?" J Law Technol Policy 201-213

Hair, Joseph F, Ronald L Tatham, Rolph E Anderson, and William C Black. 1998. Multivariate Data Analysis. 5th. Englewood Cliffs Prentice-Hall

Justice, Montana Department of. 2014. Governor bullock, attorney general fox secure victory over REAL ID. July 22. https://dojmt.gov/governor-bullock-attorney-general-fox-secure-victory-over-real-id/\#more32469

Kachigan SK (1991) Multivariate statistical analysis: a conceptual introduction. Radius Press, New York, NY

Keller SN (2017) Montana REAL ID final 12017. MSU Billings, Billings

Krane D (2007) The middle tier in American federalism: state government policy activism during the bush presidency. Publius 37:453-477

MacKenzie SB, Podsakoff PM (2012) Common method bias in marketing: causes, mechanisms, and procedural remedies. J Retail 88:542-555

Mcguire W (2000) Standing on the shoulders of the ancients: consumer research, persuasion, and figurative language. J Consum Res 27:109-114

Montana State Legislature (2007a). April 7. http://leg.mt.gov/bills/2007/billpdf/HB0287.pdf

Montana State Legislature. 2007b. "House bill 366." Montana State Legislature May 1. http://leg.mt. gov/bills/2017/billhtml/SB0366.htm

National Conference of State Legislatures. n.d. History Behind the Real ID Act. http://www.ncsl. org/research/transportation/history-behind-the-real-id-act.aspx

Otjen AJ, Ollivant R (2018). Real ID Focus Group (February 22)

Podsakoff PM, Organ DW (1986) Self-reports in organizational research: problems and prospects. J Manag 12(4):531-544

Regan PM, Deering CJ (2009) State opposition to REAL ID. Publius 39(3):476-505 
Shannon CW, Weaver W (1949) The mathematical theory of communication. Press Uol, New York Spector PE (2006) Method variance in organizational research: truth or urban legend? Organ Res Methods 9(2):221-232

Stata Press. 2013. "Stat Base Reference manual release 13.” https://www.stata.com/manuals13/rologit.pdf

Tourangeau R, Rips LJ, Rasinski K (2000) The psychology of survey response. Cambridge University Press, Oxford, United King

United States Congress, Senate. (2005). "Public Law 109-13." U.S. Government Publishing Office. May 11. https://www.gpo.gov/fdsys/pkg/PLAW-109pub113/pdf/PLAW-109publ13.pdf

United States Senate. 2008. "S. Hrg. 110-555, the impact of Implimentation." Homeland Security Digital Library April 29. http://www.hsdl.org/?abstract\&did=35475

Vehicles, Montana Division of Motor. (2018). Montana REAL ID web site. Helena, MT, May 25. www. mtrealid.gov.

Witte, Kim. (1996). "Fear as motivator, fear as inhibitor: Using the extended parallel process model to explain fear appeal successes and failures." Handbook of communication and emotion. Academic Press, 423450.

Publisher's note Springer Nature remains neutral with regard to jurisdictional claims in published maps and institutional affiliations.

\section{Affiliations}

\section{Sarah N. Keller ${ }^{1} \cdot$ Timothy J. Wilkinson $^{2} \cdot$ A. J. Otjen ${ }^{3}$}

1 Department of Communication and Theatre, Montana State University Billings, Billings, MT, USA

2 School of Business, Whitworth University, Spokane, WA, USA

3 College of Business, Montana State University Billings, Billings, MT, USA 